\title{
Selection of treatment modalities in children with spastic cerebral palsy
}

\author{
Paul SteinboK, B.Sc., M.B.B.S., F.R.C.S.(C) \\ Division of Pediatric Neurosurgery, Department of Surgery, British Columbia's Children's Hospital \\ and University of British Columbia, Vancouver, British Columbia, Canada
}

\begin{abstract}
$\checkmark$ The purpose of this report was to outline the various options currently used for treatment of spastic cerebral palsy $(\mathrm{CP})$ and to discuss factors involved in selecting the appropriate treatment modalities for the individual child. In a review of the literature and his personal observations, the author presents an outline of treatment options and the criteria for using each. Therapeutic options include the following: physiotherapy; occupational therapy; oral spasmolytic and antidystonic drugs; botulinum toxin injections; orthopedic procedures; continuous infusion of intrathecal baclofen (ITB); selective dorsal rhizotomy (SDR); and selective peripheral neurotomy. The most commonly used neurosurgical procedures are ITB pump placement and SDR, and these are discussed in the most detail. The author's personal schema for assessment of the child to determine the nature of the hypertonia, the impact of the hypertonia, and the appropriate therapeutic intervention is presented. There are factors that help guide the optimal treatment modalities for the child with spastic CP. The treatment of these children is optimized in the setting of a multidisciplinary team.
\end{abstract}

\author{
KEY WORDS • spasticity • dystonia • hypertonia • rhizotomy • baclofen • \\ treatment planning
}

$\mathrm{S}$ ELECTION of the most appropriate treatment modality for a patient with spastic CP requires that all parties involved, including the caregivers, understand and have similar expectations for what might be achieved by interventions. Treatments may be used to relieve hypertonia and/or improve the patient's range of movement, but these outcomes can be considered a means to an end. The real goals of treatment are not simply reduced tone or improved range of movement, but also include improved motor function, increased mobility, increased independence, decreased discomfort, and easier care. To make the most appropriate recommendations, the management team must be familiar with and prepared to discuss the pros and cons of the various options available.

Children may be referred for management of their "spastic" CP, but it is important to recognize that the label of "spasticity" applied to these patients may or may not be correct. Clarification of the definitions of the various disorders that might be encountered in children with socalled spastic CP is important and has been published recently by the Task Force on Childhood Motor Disorders. ${ }^{71}$ These children have hypertonia, which has been defined by the task force simply as "abnormally increased resistance to externally imposed movement about a joint." It may be caused by spasticity, dystonia, or rigidity, individually or in combination. In children with $\mathrm{CP}$, rigidity as seen

Abbreviations used in this paper: $\mathrm{ADL}=$ activities of daily living; $\mathrm{CP}=$ cerebral palsy; GABA $=\gamma$-aminobutyric acid; GMFM $=$ Gross Motor Function Measure; ITB = intrathecal baclofen; RCT = randomized controlled trial; $\mathrm{SDR}=$ selective dorsal rhizotomy; $\mathrm{SPN}=$ selective peripheral neurotomy. typically in parkinsonian patients occurs rarely, if ever, so that in practice one has to determine whether the hypertonia is due to spasticity, dystonia, or a combination of these. According to Sanger, et al., ${ }^{71}$

'Spasticity' is defined as hypertonia in which 1 or both of the following signs are present:

1) resistance to externally imposed movement increases with increasing speed of stretch and varies with the direction of joint movement, and/or 2) resistance to externally imposed movement rises rapidly above a threshold speed or joint angle.

The second criterion defines one aspect of the spastic catch, which may be felt on examination. After the rise in resistance, there may be a rapid decrease in resistance if the externally imposed force is maintained, provoking the so-called clasp-knife response. Spasticity is part of the upper motor neuron syndrome and usually coexists with other motor symptoms and signs. These include hyperreflexia, clonus, reflex overflow, a Babinski response, weakness, and incoordination.

Similar to earlier definitions, ${ }^{24,25}$ in Sanger, et al. ${ }^{71}$ dystonia is defined as a "movement disorder in which involuntary sustained or intermittent muscle contractions cause twisting and repetitive movements, abnormal postures, or both." Dystonia may cause hypertonia, but it may also be present in the absence of hypertonia.

\section{Management Options}

Nonneurosurgical options for the treatment of so-called spastic CP include the following, among others: physiotherapy; occupational therapy; oral spasmolytic and antidystonic drugs; botulinum toxin injections; and orthopedic procedures such as tendon lengthening. Neurosurgical 
interventions, which are discussed more fully elsewhere in this issue, include pump implantation for continuous infusion of ITB, and procedures such as SDR and SPN.

\section{Nonneurosurgical Options}

One of the major problems encountered in the child with spastic CP is the development of joint contractures caused by imbalance between the spastic agonists and the weaker antagonists. These contractures most commonly affect the ankle plantar flexors, which may be part of the equinus deformity, and the hamstrings, leading to a knee flexion deformity. Stretching of the spastic muscles may help prevent the development of contractures, but to be most effective, such stretching needs to be done for at least 6 hours daily. ${ }^{82}$ Stretching exercises may be performed by physiotherapists, who also teach caregivers to do these exercises repeatedly. Orthotic devices may be helpful in keeping spastic muscles stretched for a more prolonged period. Occupational therapists assist the child in optimizing his or her ability to perform ADL. To achieve this, the needs of the child with respect to eating, positioning, splinting, and equipment are addressed.

A number of drugs have been used orally to reduce symptoms in children with spastic diplegic or quadriplegic CP. ${ }^{42,85}$ These drugs include baclofen, dantrolene, clonazepam, diazepam, and tizanidine. Baclofen, whose chemical name is 4-amino-3-(4-chlorophenyl)-butyric acid, is a synthetic GABA agonist that acts selectively on both pre- and postsynaptic $\mathrm{GABA}_{\mathrm{B}}$ receptors to reduce excitatory synaptic transmission. Baclofen has been used orally since the early 1970s as an antispasmodic agent. The drug is absorbed well after oral administration, but has low lipid solubility and does not cross the blood-brain barrier readily. ${ }^{5,39}$ Oral baclofen has not been particularly effective in reducing spasticity of cerebral origin, specifically in children with CP. ${ }^{57,84}$ The value of oral baclofen has been limited by the common occurrence of sedation at the dose levels needed for relief of spasticity. Other less common side effects have included behavioral changes, confusion, ataxia, urinary frequency, and insomnia. ${ }^{5,57}$ Dantrolene inhibits the release of calcium from the sarcoplasmic reticulum, and thus weakens muscles, thereby reducing tone. Diazepam and clonazepam decrease spasticity by increasing presynaptic inhibition in the spinal cord, but tend to cause unacceptable sedation. Tizanidine is an $\alpha_{2}$-adrenergic agonist that increases noradrenergic inhibition in the spinal cord. This agent's side effects include hypotension, drowsiness, and muscle weakness, with drowsiness being the most common limiting problem.

In children in whom it is a significant component of the hypertonic $\mathrm{CP}$, oral medications directed at the dystonia may be used. In children with dystonia in whom the supposed CP is atypical or progressive, a trial of levodopa may be indicated, because occasionally a patient will have levodopa-responsive dystonia. ${ }^{56}$ When the diagnosis is clearly CP, baclofen, trihexyphenydil, clonazepam, and tetrabenazine have occasionally been effective in improving dystonia, but more often than not these medications are ineffective. ${ }^{65}$

Intramuscular injections of botulinum toxin A have been used since the 1970s for the treatment of strabismus, and more recently its use has been expanded to a variety of dystonias and also spasticity, including that caused by
CP..$^{14,44}$ The effect of botulinum toxin is temporary, lasting from 2 to 6 months. In CP, botulinum toxin has been used primarily to treat dynamic equinus and, to a lesser extent, hip adductor spasms. In a number of open trials and also in RCTs, improvement in spasticity and possible improvement in function at 3 to 6 months have been indicated, but there is no information on the longer-term effectiveness of this treatment. ${ }^{4,44}$ There have been few side effects of botulinum toxin injections, and this, together with the transient nature of the responses and the ease of administration, has made it an increasingly popular intervention in $\mathrm{CP}$. The enthusiasm for the use of botulinum toxin should be tempered by the recognition that the evidence for its effectiveness in CP is weak.

Orthopedic surgery most commonly involves tendonlengthening operations to try to restore balance once contractures have occurred, or to prevent hip subluxation in children with severe hip adductor spasticity. These procedures weaken the muscles, and because the underlying spasticity has not been treated, shortening of the muscles tends to occur as the child grows, and repeated tendon lengthening procedures may be necessary. Tendon transfers may be done to augment the strength of a weak muscle group. In the child older than 4 years of age, femoral derotation osteotomies may be done to treat internal rotation of the lower limbs, and in the child approaching the age of skeletal maturity, arthrodesis of the ankle can add stability to the foot. It is important to recognize that even if one is successful in relieving spasticity by using some of the treatment modalities described later, many of the aforementioned management techniques may still be required to optimize the child's functioning.

\section{Neurosurgical Procedures Directed at Spasticity}

The major neurosurgical interventions used currently in the treatment of spasticity in CP are SDR and pump implantation for continuous infusion of ITB. It is thought that SPNs may also be a therapeutic option.

Dorsal (Posterior) Rhizotomy. One of the common neurosurgical procedures for spastic $\mathrm{CP}$ is the partial lumbosacral dorsal rhizotomy. The rationale for this procedure is that input entering the spinal cord through the posterior roots has a net excitatory effect on the anterior roots, and that by decreasing the input from the dorsal roots one can reduce spasticity. This concept and the initial dorsal rhizotomy procedure are a century old.

Transection of posterior lumbar and sacral nerve roots for the treatment of lower-limb spasticity was first reported in the early 1900s by Foerster, ${ }^{29}$ who described a series of patients in whom total sectioning of the posterior nerve roots of L-2 and L-3 as well as L-5 and S-1 (sparing L-4) was performed. Relief of spasticity in the majority of patients was noted. In the 1960s, Gros, et al., ${ }^{33}$ modified the original procedure described by Foerster and performed partial posterior rhizotomies, with nonselective sectioning of $80 \%$ of each of the nerve roots from L-1 to S- 1 . Further refinements of the partial rhizotomy procedure have followed two different paths.

One refinement was a selective partial rhizotomy procedure ("sectorial rhizotomy"), wherein the extent of the surgery was tailored to the clinical status of the individual patient. ${ }^{67}$ Lower-limb spasticity was categorized clinically into "disabling" compared with "beneficial" spasticity, and 
the goal of the modified procedure was to relieve, if possible, only spasticity that was thought to be disabling. During the procedure, electrophysiological stimulation of the posterior rootlets was performed to identify the muscle groups primarily innervated by each individual posterior nerve rootlet. This allowed sectioning of rootlets feeding into muscle groups that were identified clinically as involved with "disabling" spasticity, while sparing nerve rootlets innervating muscle groups that were identified as providing "beneficial" spasticity.

A different approach, originally proposed in 1978 by Fasano, et al.,26 involved the selection of the posterior rootlets to be cut based on the functional electrophysiological results of intraoperative electrical stimulation, and not on the clinical findings. It was thought that by stimulating lumbosacral posterior nerve rootlets and recording responses from anterior roots and muscles, one could identify the nerve rootlets that were relatively more involved in the maintenance of spasticity and preferentially cut them, thus reducing spasticity while maintaining maximal preservation of neural tissue..$^{27}$ The validity of the concept underlying this electrophysiological SDR and the importance of electrophysiological guidance for a good outcome have been questioned. ${ }^{19,34,46,64,78,86}$ The original electrophysiological criteria have been modified, and the current criteria of involvement in spasticity include spread of the response contralaterally and suprasegmentally, and an incremental or multiphasic pattern in the response to a 50$\mathrm{Hz}$ tetanic stimulus. Whether these newer criteria are valid and how important electrophysiological guidance is for a good outcome are not known. There have been significant variations among centers in the way the procedure is done. ${ }^{77,81}$ There has been a trend toward relying less on the electrophysiological responses and more on the clinical findings, and in many centers a combination of the two is used. Outcomes after SDR have been well characterized and reviewed. ${ }^{74}$ There is very strong evidence that SDR results in improvements in lower-limb spasticity and an increase in the range of movement at the lower-limb joints with no loss of strength. ${ }^{23,50,74}$ There is a moderate degree of certainty that these improvements in the impairment dimension are maintained up to 5 years after SDR, and some weaker evidence that the improvements are maintained even longer. ${ }^{74}$ In ambulatory patients, there is strong evidence for increased stride length after SDR and moderate evidence for increased gait velocity. There is a moderate degree of certainty for improved sitting ability in more than $70 \%$ of patients and an improved level of ambulation in more than $50 \%$ of patients who were not already independent ambulators prior to SDR. There is strong evidence, including that from three RCTs, for an improvement in motor function after SDR, as assessed with the GMFM scale..$^{37,48-50,79,87}$ However, in only two of the three RCTs was the improvement in GMFM scores statistically more than in a control group receiving physiotherapy only. ${ }^{79,87}$ In the other RCT, there was no difference between the SDR and the control group with respect to GMFM improvement alone..$^{48}$ In a metaanalysis of these three RCTs, there was a small but statistically significant improvement in the patients undergoing SDR plus physiotherapy compared with those receiving physiotherapy only. ${ }^{15}$

As one examines the impact of SDR on the child's abil- ity to engage in ADL, there is good evidence from prospective case series in which patients were evaluated using validated assessment tools (either the Functional Independence Measure for Children or the Pediatric Evaluation of Disability Inventory) that there are improvements in self care and the performance of ADL after SDR. ${ }^{16,22,45,51,55}$ These findings are supported by those in other prospective case series in which less well-validated outcome tools were used. ${ }^{74}$

In addition to the impact of SDR on the lower limbs, there have been well-documented suprasegmental improvements. These have been demonstrated most convincingly for upper-limb function by using a validated tool, namely the Quality of Upper Extremities Skills Test ${ }^{45}$ and the fine motor skills section of the Peabody Developmental Motor Scales test, ${ }^{52}$ to measure upper-limb function. There is a single small study in which investigators have suggested improvement in cognitive function. ${ }^{20}$

The complications of SDR have been few in most series. ${ }^{3,80}$ Urinary incontinence is probably the most troublesome problem. Transient urinary retention is frequent, with an incidence of between 1.25 and $24 \%,,^{21,26,60,80}$ but permanent urinary retention or incontinence is rare. Transient dysesthesias lasting up to a few weeks have been reported in 2.5 to $40 \%$ of patients, ${ }^{3,49,80}$ but the reported incidence of permanent hypesthesia after SDR is very low, generally varying from 0 to $6 \%$ in different series, and usually without functional significance..$^{2,11,28,80} \mathrm{~A}$ concern often raised is whether SDR will reduce function in children who are using their spasticity to stand and who have poor underlying lower-limb strength. In our experience, no patient's condition was worsened in this manner, and this may be more of a theoretical than a practical concern.

One of the concerns in children with significant spasticity affecting the hips is the complication of hip subluxation. With respect to this complication, fewer than $20 \%$ of patients worsened and the vast majority were stable $(43-80 \%)$ or actually showed improvement $(9-38 \%)$ in the amount of hip subluxation after SDR. ${ }^{35-37,59}$

The surgical procedure for SDR is performed either at the level of the conus via one- or two-level laminectomies, or at the level of the root exit foramina via multilevel laminectomies or laminotomies, with replacement of the laminar flap. A concern regarding laminectomies or laminotomies in young children is the later development of back pain or spinal deformity. ${ }^{88}$ Back pain occurring weeks to years after SDR has been reported in 4 to $7 \%$ of patients, ${ }^{1,63,80}$ but it is unusual for this to be severe enough to interfere with ADL or to lead to hospitalization.

The issue of spinal deformity is more contentious. It has been recognized for a long time that children with spastic $\mathrm{CP}$ are at higher risk of spinal deformity, particularly scoliosis, than the normal population, ${ }^{13}$ and that nonambulatory patients with spastic quadriplegia constitute the population at highest risk. It has been suggested in a number of recent reports that SDR performed via multilevel laminoplasties or laminectomies may increase the incidence of thoracolumbar scoliosis, kyphosis, and hyperlordosis in these at-risk children with CP. ${ }^{38,76,83}$ The possible increased risk of spinal deformity after SDR is noted primarily in nonambulatory patients with spastic quadriplegia, ${ }^{73,76}$ who currently tend to be treated with ITB rather than rhizotomies. It has been suggested that this potential complica- 
tion can be reduced by performing the procedure via oneor two-level laminectomies at the level of the conus, but there is no evidence at present to support this hypothesis.

Pump Implantation for ITB. Baclofen reduces limb spasticity by its effect on $\mathrm{GABA}_{\mathrm{B}}$ receptors, which are maximal in layers II and III of the dorsal gray matter of the spinal cord. ${ }^{66}$ As mentioned previously, oral baclofen has a limited effect on spasticity in CP, in part because of an inability to bypass the blood-brain barrier and achieve a high enough concentration at the receptor sites in the spinal cord, and in part because systemic administration also affects the central $\mathrm{GABA}_{\mathrm{B}}$ receptors, which results in toxicity. With continuous spinal ITB infusions, the concentrations of baclofen typically achieved in the spinal subarachnoid fluid are 10 to 80 times higher than those present after oral administration, ${ }^{39,54}$ leading to a much greater therapeutic effect. The therapeutic ratio is also improved for at least two reasons: first, the CSF concentration intracranially is less than intraspinally, ${ }^{43}$ and second, the intracranial $\mathrm{GABA}_{\mathrm{B}}$ receptors are not as close to the surface as the spinal ones, and because the baclofen diffuses poorly into neural tissue, the concentration of baclofen in tissue at the intracranial receptor sites is relatively less than at the spinal receptor sites.$^{58}$ In addition to an effect on spasticity, baclofen also improves dystonia. The site of action of baclofen in the treatment of dystonia is thought to be supraspinal. $^{8}$

To achieve a clinically useful prolonged effect, ITB must be given by continuous infusion through an implanted pump. Before implantation of the pump, most patients undergo a trial of bolus doses of ITB to confirm a positive effect of the drug in reducing hypertonia. For patients with generalized dystonia, successful reduction of their symptoms during the test phase may require that the baclofen be given intrathecally through an external infusion pump. The most commonly used pump is the programmable Synchromed device (Medtronic, Inc., Minneapolis, MN). This is a battery-powered pump that can be adjusted using a radiofrequency-controlled external wand and programming computer to deliver variable flow rates, continuous and/or bolus infusions, or a set total dose. The pump is implanted into a subcutaneous or subfascial pocket in the anterior abdominal wall. A catheter is inserted into the lumbar subarachnoid space at the L3-4 or L4-5 level, and is threaded superiorly to place the tip at approximately $\mathrm{T} 10$ 12 for spastic diplegia, C5-T2 for spastic quadriparesis, or C1-4 for generalized secondary dystonia. ${ }^{9}$

The evidence for the efficacy of continuous infusion of ITB in children with CP was reviewed in detail recently. ${ }^{17}$ There is consistent evidence from multiple case reports, case series, "N of 1" RCTs, and two double-blind placebocontrolled studies that a bolus dose of ITB reduces spasticity, clonus, and spasms. ${ }^{17}$ In retrospective and open prospective studies, continuous infusion of ITB has been shown to decrease lower-limb spasticity in children with $\mathrm{CP}$. There may also be a reduction in upper-limb spasticity, but the evidence is not as strong. Improvements in ambulation and ADL have also been demonstrated in prospective studies, but the evidence is not as conclusive as it is for a reduction in spasticity. ${ }^{7,10,31}$

More recently, continuous infusion of ITB has been used for the treatment of hypertonic dystonia in children. There is good evidence that ITB reduces the severity of general- ized dystonia in patients with dystonic or spastic/dystonic CP. ${ }^{8}$ The reduction in dystonia was associated with improved quality of life and ease of care.

Complications associated with ITB are common, and may be related to the drug, to local problems with the surgical procedure, or the hardware. The most common drugrelated problem from ITB is mild sedation, which requires a decrease in the dose. Less commonly there may be dizziness, blurred vision, and slurred speech., ${ }^{5,61}$ Increased frequency or precipitation of seizures has also been reported. ${ }^{18,41,69}$ Life-threatening overdoses, characterized by severe respiratory depression, coma, hypotension, and bradycardia, can also occur. In patients with suspected drug overdoses, the diagnosis is supported by the findings of weakness, flaccidity, and areflexia in both lower and upper limbs. Sudden withdrawal of ITB after long-term use, as might occur with a blockage to the system or pump failure, may result in hallucinations, seizures, confusion, psychotic behavior, rebound severe spasticity, and hyperthermia. ${ }^{40,47,68,72}$ If the diagnosis is made early, oral baclofen or benzodiazepines may be given, and oral dantrolene has also been used to help prevent or treat hyperthermia. ${ }^{32}$ Reinfusion of baclofen into the subarachnoid space as a bolus through the pump or by lumbar puncture may reverse the symptoms. If it is decided to discontinue continuous ITB therapy, this should be done gradually, and the patient should receive oral baclofen. Failure of the pump occurs in 5 to $10 \%$ of cases, and requires its replacement. ${ }^{18,61}$

Other local problems related to the infusion system include the following: seromas around the pump; erosion of the skin over the device; disconnection at a connector site; a break, kinking, or displacement of the intrathecal catheter; and leakage of CSF at the catheter insertion site. ${ }^{5,12,30}$ Some of these complications have been reduced as surgeons have gained experience inserting the pumps and with improved catheter systems, particularly since the development of thicker-walled catheters. ${ }^{62}$ The local problems tend to be aggravated in children. The pumps are large and protrude markedly in the anterior abdominal wall, especially in young or very thin children, although this is less of a problem with subfascial placement. In children with spastic quadriplegia, who are often restrained in a wheelchair and who tend to be thin, the protruding pump may be irritated repeatedly by the restraints that are used, leading to a higher incidence of local complications.

As in any surgery involving implants, infection is a major concern. Local infection of the wound or subcutaneous pump pocket has been reported in up to $20 \%$ of patients. ${ }^{30,53}$ Pump erosion through the skin and subsequent contamination of the device is not unusual, especially in children. Local infections can sometimes be eradicated with the use of systemic antibiotic drugs, but more often the pump has to be removed. Meningitis has been documented, both during trials of repeated intrathecal injections before insertion of the pump and after its implantation.

Continuous ITB therapy requires long-term medical attention to refill the pump, to adjust the dose to obtain the desired effect, to replace the pump when the battery fails, and to address the various complications previously mentioned. Should spasticity recur in a patient receiving continuous ITB, the practitioner needs to determine whether tolerance to the drug has occurred or whether there is a problem with the delivery of the drug intrathecally. Hence, 
pump failure or some mechanical problem with the system has to be ruled out.

Finally, the expense involved with the continuous infusion of ITB must be considered. The pump itself costs more than $\$ 10,000$ US and has to be replaced periodically. In addition, there are ongoing costs associated with the refills and with management of the complications that may occur. ${ }^{75}$

\section{Assessment of the Child With Spastic CP}

The first issue in the assessment of the child with $\mathrm{CP}$ who is referred for management of spasticity is to determine whether the increased tone relates to spasticity, dystonia, or both, and what is the relative contribution of each to the overall hypertonia. Having determined the nature of the hypertonia, the next question is whether it is the hypertonia or some other problem, such as contractures, incoordination, or weakness that is inhibiting the child's functioning or the ability of the caregivers to look after the child. The motor disorder in children with hypertonic CP is complex, and is the result of a number of factors in addition to the effects of spasticity and/or dystonia. Weakness and incoordination are common. There usually is co-contraction of agonists and antagonists, excessive reflex spread to other muscle groups, and reduced selective motor control (defined as impairment of the ability to isolate the activation of muscles in a selected pattern in response to the demands of a voluntary posture or movement). ${ }^{70}$ As the child gets older, contractures and deformities of the extremities often develop, particularly knee flexor and ankle plantar flexor contractures. There may be hip dislocations, rocker-bottom feet, and spinal deformity, especially scoliosis, which may add to the motor dysfunction and discomfort and to the difficulty in providing care. An element of impaired sensory perception probably adds to the impairment of motor function as well.

It is important to find out from the parents or other caregivers what they think is holding the child back or making care difficult. It is instructive to hear how they think the child would benefit if the hypertonia, but nothing else, in the lower or upper limbs was reduced. If it is not thought that reducing hypertonia will improve function, the child is not a candidate for a hypertonia-relieving procedure.

If the child has spasticity and might benefit functionally or with respect to the ease of receiving care if spasticity in multiple muscle groups in the lower limbs were relieved, the practitioner will consider options such as ITB or SDR. The ambulatory potential must be assessed, and an attempt is made to determine if reduction in lower-limb spasticity might be detrimental to the child's ambulatory function, because the child may be using the spasticity to support weight in the upright position. This is one of the most difficult issues. In our experience, children who walk independently, without a walker or crutches, and younger children who crawl on their knees and arms have enough underlying strength in the lower limbs so that the lessening of spasticity is not a concern.

For the other patients, the child's ability to rise in a slow, graded fashion from the squatting position is assessed. If the child is able to do this with the examiner supporting the arms or upper body minimally, the probability is high that there is adequate underlying quadriceps strength to support the child's weight if the spasticity is reduced. In the patient with spastic quadriplegia, in whom ambulation is not a realistic goal, the involvement of spasticity in supporting the child in the upright position is also a concern. Many of these children, who get around in wheelchairs, use their spasticity to assist in standing transfers. They may be worse functionally if that spasticity is reduced and they are no longer able to support their weight. This may not appear to be a major issue in the young child who is easily lifted, but it attains increasing importance as the child gets older, heavier, and more difficult to lift.

At the completion of the assessment, it is critical to ascertain what the expectations and hopes of the parents or other primary caregivers are and to ensure that they are realistic. This perception should be documented, because almost all parents are seeking a "cure" for their child's motor problems, or if not, they hope that their child will walk, and many have unrealistic expectations of the treatment that is proposed. Even if the child improves functionally, these parents may not be happy because he or she does not meet their expectations. In most cases, one can allow many months to pass before treating the hypertonia, and the parents are usually advised to take some time to think about the suggested recommendations, especially if an operation is advised. Occasionally, when the child's hips are dislocating because of excessive hip abductor spasticity, a more urgent intervention is recommended; even then, however, one may be able to temporize with a treatment such as intramuscular botulinum toxin.

If it is determined that treatment of the hypertonia is indicated, one then needs to decide what intervention would be most appropriate. In children in whom the functionally important spasticity is predominantly in one muscle group (such as the ankle plantar flexors or hamstrings), consideration is given to botulinum toxin or an orthopedic tendon-lengthening procedure. In some centers, such patients could be considered for an SPN. Even when the functionally important spasticity affects one muscle group, there is usually spasticity throughout the lower limbs, and an argument can be made for performing a dorsal rhizotomy or using ITB to decrease the lower-limb spasticity more diffusely in this patient population. However, we opt for a simpler or less destructive procedure if the functional results might reasonably be expected to be similar.

Intrathecal baclofen is the intervention of choice in children suffering from spastic dystonic quadriplegia from near drowning. ${ }^{12}$ In patients in whom dystonia rather than spasticity is inhibiting function, ITB is indicated. ${ }^{8}$ Children with quadriplegia caused by spastic $\mathrm{CP}$ affecting the upper limbs more than the lower ones, or children with severe opisthotonic posturing, may be considered for ITB because it is possible to direct the subarachnoid catheter to the cervicothoracic region and treat the hypertonia in both the upper and lower limbs. ${ }^{9}$

Intrathecal baclofen is often proposed in preference to SDR in children with spastic diplegic CP when there is concern that spasticity is needed for standing or walking support. ${ }^{6}$ The argument is that the dose of baclofen is titratable, and in the worst-case scenario, if the result is unsatisfactory, the treatment is reversible. This concern about the possible loss of ability to stand or walk may be focused on a problem that is more theoretical than real. 
Our experience has been that these patients, about whom we have agonized, have done well after SDR, with no child losing the ability to walk or stand after that procedure. Hence, our preference has been to recommend an SDR as opposed to ITB in this situation. In these children we will limit the extent of section of the dorsal rootlets that cause primarily quadriceps contraction when stimulated intraoperatively.

Other indications for ITB include diplegia in older patients, particularly those older than 16 years, and spastic quadriplegia in children in whom the lower-limb spasticity is disabling or making care difficult. ${ }^{6}$ These children may also meet the criteria to be considered for SDR, and there are no studies in which these two treatment modalities are compared in these populations. In these situations, in which either ITB or SDR might be considered to be effective and indicated options, one has to work with the family to determine in each individual circumstance what the preferred option might be. One must consider not only the pure medical outcomes but also the logistics of achieving the postoperative care required after SDR compared with that required for management of continuous infusion of ITB and the costs involved for these options. Compared with ITB therapy, SDR is a more invasive procedure, but it requires little long-term management, does not require reoperation, and does not require repeated visits to a medical center for refills. For a family living many hours away from a medical center, the difficulties of repeatedly accessing medical care may be an important consideration.

\section{Conclusions}

The management of motor impairment in the child with hypertonic CP should be multidisciplinary, and usually involves a physiotherapist, occupational therapist, developmental pediatrician, orthopedic surgeon, and orthotist, in addition to the neurosurgeon. The neurosurgeon is usually asked for an opinion about the management of the spasticity and/or hypertonia. It is important that he/she appreciates the various neurosurgical and nonneurosurgical interventions available for the relief of spasticity, and recognizes that the goal of treatment is not the relief of hypertonia per se, but the improvement of function, comfort, or care. The neurosurgeon should work as part of a team, which includes the parents or caregivers, to identify the best management option to optimize the outcome. Furthermore, if a neurosurgical intervention directed at the relief of hypertonia is believed to be indicated, the best outcome is achieved with input from physiotherapists, occupational therapists, orthotists, and orthopedic surgeons in the postoperative period.

\section{References}

1. Abbott R: Sensory rhizotomy for the treatment of childhood spasticity. J Child Neurol 11: S36-S42, 1996

2. Abbott R, Forem SL, Johann M: Selective posterior rhizotomy for the treatment of spasticity: a review. Childs Nerv Sys 5: 337-346, 1989

3. Abbott R, Johann-Murphy M, Shiminski-Maher T, Quartermain D, Forem SL, Gold JT, et al: Selective dorsal rhizotomy: outcome and complications in treating spastic cerebral palsy. Neurosurgery 33:851-857, 1993

4. Ade-Hall R, Moore A: Botulinum toxin type A in the treatment of lower limb spasticity in cerebral palsy. Cochrane Database Syst Rev, 2001

5. Albright AL: Baclofen in the treatment of cerebral palsy. J Child Neurol 11:77-83, 1996

6. Albright AL: Intrathecal baclofen in cerebral palsy movement disorders. J Child Neurol 11: S29-S35, 1996

7. Albright AL, Barron WB, Fasick MP, Polinko P, Janosky J: Continuous intrathecal baclofen infusion for spasticity of cerebral origin. JAMA 270:2475-2477, 1993

8. Albright AL, Barry MJ, Shafton DH, Ferson SS: Intrathecal baclofen for generalized dystonia. Dev Med Child Neurol 43:652-657, 2001

9. Albright AL, Turner M, Pattisapu JV: Best-practice surgical techniques for intrathecal baclofen therapy. J Neurosurg 104 (4 Suppl):233-239, 2006

10. Almeida GL, Campbell SK, Girolami GL, Penn RD, Corcos DM: Multidimensional assessment of motor function in a child with cerebral palsy following intrathecal administration of baclofen. Phys Ther 77:751-764, 1997

11. Arens LJ, Peacock WJ, Peter J: Selective posterior rhizotomy: a long-term follow-up study. Childs Nerv Syst 5:148-152, 1989

12. Armstrong RW, Steinbok P, Cochrane DD, Kube SD, Fife SE, Farrell K: Intrathecally administered baclofen for treatment of children with spasticity of cerebral origin. J Neurosurg 87: 409-414, 1997

13. Balmer GA, MacEwen GD: The incidence and treatment of scoliosis in cerebral palsy. J Bone Joint Surg Br 52:134-137, 1970

14. Bentivoglio AR, Albanese A: Botulinum toxin in motor disorders. Curr Opin Neurol 12:447-456, 1999

15. Bjornson KF, McLaughlin JF: The measurement of healthrelated quality of life (HRQL) in children with cerebral palsy. Eur J Neurol 8 (Suppl 5):183-193, 2001

16. Bloom KK, Nazar GB: Functional assessment following selective posterior rhizotomy in spastic cerebral palsy. Childs Nerv Sys 10:84-86, 1994

17. Butler C, Campbell S: Evidence of the effects of intrathecal baclofen for spastic and dystonic cerebral palsy. AACPDM Treatment Outcomes Committee Review Panel. Dev Med Child Neurol 42:634-645, 2000

18. Coffey RJ, Cahill D, Steers W, Park TS, Ordia J, Meythaler J, et al: Intrathecal baclofen for intractable spasticity of spinal origin: results of a long-term multicenter study. J Neurosurg 78:226-232, 1993

19. Cohen AR, Webster HC: How selective is selective posterior rhizotomy? Surg Neurol 35:267-272, 1991

20. Craft S, Park TS, White DA, Schatz J, Noetzel M, Arnold S: Changes in cognitive performance in children with spastic diplegic cerebral palsy following selective dorsal rhizotomy. Pediatr Neurosurg 23:68-75, 1995

21. Deletis V, Vodusek DB, Abbott R, Epstein FJ, Turndorf H: Intraoperative monitoring of the dorsal sacral roots: minimizing the risk of iatrogenic micturition disorders. Neurosurgery 30:72-75, 1992

22. Dudgeon BJ, Libby AK, McLaughlin JF, Hays RM, Bjornson KF, Roberts TS: Prospective measurement of functional changes after selective dorsal rhizotomy. Arch Phys Med Rehabil 75:46-53, 1994

23. Engsberg JR, Ross SA, Wagner JM, Park TS: Changes in hip spasticity and strength following selective dorsal rhizotomy and physical therapy for spastic cerebral palsy. Dev Med Child Neurol 44:220-226, 2002

24. Fahn S: Concept and classification of dystonia. Adv Neurol 50: $1-8,1988$

25. Fahn S, Bressman SB, Marsden CD: Classification of dystonia, in Fahn S, Marsden CD, DeLong M (eds): Dystonia 3. Philadelphia: Lippincott-Raven, 1998, Vol 78, pp 1-10

26. Fasano VA, Broggi G, Barolat-Romana G, Sguazzi A: Surgical treatment of spasticity in cerebral palsy. Childs Brain 4: 289-305, 1978

27. Fasano VA, Broggi G, Zeme S: Intraoperative electrical stimu- 
lation for functional posterior rhizotomy. Scand J Rehabil Med Suppl 17:149-154, 1988

28. Fasano VA, Broggi G, Zeme S, Lo Russo G, Sguazzi A: Longterm results of posterior functional rhizotomy. Acta Neurochir Suppl 30:435-439, 1980

29. Foerster O: On the indications and results of the excision of posterior spinal nerve roots in man. Surg Gynecol Obstetrics 16: 463-474, 1913

30. Gardner B, Jamous A, Teddy P, Bergstrom E, Wang D, Ravichandran $\mathrm{G}$, et al: Intrathecal baclofen-a multicentre clinical comparison of the Medtronics Programmable, Cordis Secor and Constant Infusion Infusaid drug delivery systems. Paraplegia 33:551-554, 1995

31. Gerszten PC, Albright AL, Barry MJ: Effect on ambulation of continuous intrathecal baclofen infusion. Pediatr Neurosurg 27:40-44, 1997

32. Gooch JL, Oberg WA, Grams B, Ward LA, Walker ML: Complications of intrathecal baclofen pumps in children. Pediatr Neurosurg 39:1-6, 2003

33. Gros C, Oaknine G, Vlahovitch B, Frerebeau P: La radicotomie selective posterioeure dans le traitment neurochirurgical de l'hypertonie pyramidale. Neurochirurgie 13:505-518, 1967

34. Hays RM, McLaughlin JF, Bjornson KF, Stephens K, Roberts TS, Price R: Electrophysiological monitoring during selective dorsal rhizotomy, and spasticity and GMFM performance. Dev Med Child Neurol 40:233-238, 1998

35. Heim RC, Park TS, Vogler GP, Kaufman BA, Noetzel MJ, Ortman MR: Changes in hip migration after selective dorsal rhizotomy for spastic quadriplegia in cerebral palsy. J Neurosurg 82:567-571, 1995

36. Hicdonmez T, Steinbok P, Beauchamp R, Sawatzky B: Hip joint subluxation after selective dorsal rhizotomy for spastic cerebral palsy. J Neurosurg 103 (1 Suppl):10-16, 2005

37. Hodgkinson I, Berard C, Jindrich ML, Sindou M, Mertens P, Berard J: Selective dorsal rhizotomy in children with cerebral palsy. Results in 18 cases at one year postoperatively. Stereotact Funct Neurosurg 69:259-267, 1997

38. Johnson MB, Goldstein L, Thomas SS, Piatt J, Aiona M, Sussman M: Spinal deformity after selective dorsal rhizotomy in ambulatory patients with cerebral palsy. J Pediatr Orthop 24: 529-536, 2004

39. Knuttson E, Lindblom U, Beissinger RL, Martensson A: Plasma and cerebrospinal fluid levels of baclofen (Lioresal) at optimal therapeutic responses in spastic paraparesis. J Neurol Sci 23:473-484, 1974

40. Kofler M, Arturo Leis A: Prolonged seizure activity after baclofen withdrawal. Neurology 42:697-698, 1992

41. Kofler M, Kronenberg MF, Rifici C, Saltuari L, Bauer G: Epileptic seizures associated with intrathecal baclofen application. Neurology 44:25-27, 1994

42. Krach LE: Pharmacotherapy of spasticity: oral medications and intrathecal baclofen. J Child Neurol 16:31-36, 2001

43. Kroin JS, Ali A, York M, Penn RD: The distribution of medication along the spinal canal after chronic intrathecal administration. Neurosurgery 33:226-230, 1993

44. Lannin N, Scheinberg A, Clark K: AACPDM systematic review of the effectiveness of therapy for children with cerebral palsy after botulinum toxin A injections. Dev Med Child Neurol 48:533-539, 2006

45. Loewen P, Steinbok P, Holsti L, MacKay M: Upper extremity performance and self-care skill changes with spastic cerebral palsy following selective posterior rhizotomy. Pediatr Neurosurg 29:191-198, 1998

46. Logigian EL, Wolinsky JS, Soriano SG, Madsen JR, Scott RM: $\mathrm{H}$ reflex studies in cerebral palsy patients undergoing partial dorsal rhizotomy. Muscle Nerve 17:539-549, 1994

47. Mandac BR, Hurvitz EA, Nelson VS: Hyperthermia associated with baclofen withdrawal and increased spasticity. Arch Phy Med Rehabil 74:96-97, 1993

48. McLaughlin JF, Bjornson KF, Astley SJ, Graubert C, Hays RM,
Roberts TS, et al: Selective dorsal rhizotomy: efficacy and safety in an investigator-masked randomized clinical trial. Dev Med Child Neurol 40:220-232, 1998

49. McLaughlin JF, Bjornson KF, Astley SJ, Hays RM, Hoffinger SA, Armantrout EA, et al: The role of selective dorsal rhizotomy in cerebral palsy: critical evaluation of a prospective clinical series. Dev Med Child Neurol 36:755-769, 1994

50. Mittal S, Farmer JP, Al-Atassi B, Gibis J, Kennedy E, Galli C, et al: Long-term functional outcome after selective posterior rhizotomy. J Neurosurg 97:315-325, 2002

51. Mittal S, Farmer JP, Al-Atassi B, Montpetit K, Gervais N, Poulin $\mathrm{C}$, et al: Functional performance following selective posterior rhizotomy: long-term results determined using a validated evaluative measure. J Neurosurg 97:510-518, 2002

52. Mittal S, Farmer JP, Al-Atassi B, Montpetit K, Gervais N, Poulin C, et al: Impact of selective posterior rhizotomy on fine motor skills. Long-term results using a validated evaluative measure. Pediatr Neurosurg 36:133-141, 2002

53. Müller H: Treatment of severe spasticity: results of a multicenter trial conducted in Germany involving the intrathecal infusion of baclofen by an implantable drug delivery system, in Lakke JPWF, Delhaas EM, Rutgers AWF (eds): Parenteral Drug Therapy in Spasticity and Parkinson's Disease. Lancaster: Parthenon Press, 1992, pp 103-113

54. Muller H, Zierski J, Dralle D, Kraus D, Mutschler E: Pharmacokinetics of intrathecal baclofen, in Muller H, Zierski J, Penn RD (eds): Local Spinal Therapy of Spasticity. Berlin: Springer-Verlag, 1988, pp 223-226

55. Nishida T, Thatcher SW, Marty GR: Selective posterior rhizotomy for children with cerebral palsy: a 7-year experience. Childs Nerv Sys 11:374-380, 1995

56. Nygaard TG, Waran SP, Levine RA, Naini AB, Chutorian AM: Dopa-responsive dystonia simulating cerebral palsy. Pediatr Neurol 11:236-240, 1994

57. O'Donnell M, Armstrong R: Pharmacologic interventions for management of spasticity in cerebral palsy. Mental Retardation and Developmental Disabilities Research Review 3: 204-211, 1997

58. Ochs GA: Intrathecal baclofen. Baillieres Clin Neurol 2: 73-86, 1993

59. Park TS, Vogler GP, Phillips LH II, Kaufman BA, Ortman MR, McClure SM, et al: Effects of selective dorsal rhizotomy for spastic diplegia on hip migration in cerebral palsy. Pediatr Neurosurg 20:43-49, 1994

60. Peacock WJ, Arens LJ: Selective posterior rhizotomy for the relief of spasticity in cerebral palsy. S Afr Med J 62:119-124, 1982

61. Penn RD: Intrathecal baclofen for spasticity of spinal origin: seven years of experience. J Neurosurg 77:236-240, 1992

62. Penn RD, York MM, Paice JA: Catheter systems for intrathecal drug delivery. J Neurosurg 83:215-217, 1995

63. Peter JC, Arens LJ: Selective posterior lumbosacral rhizotomy for the management of cerebral palsy spasticity. A 10-year experience. S Afr Med J 83:745-747, 1993

64. Pollack MA: Limited benefit of electrophysiological studies during dorsal rhizotomy. Muscle Nerve 17:553-556, 1994

65. Pranzatelli MR: Oral pharmacotherapy for the movement disorders of cerebral palsy. J Child Neurol 11 (Suppl 1): S13-S22, 1996

66. Price GW, Wilkin GP, Turnbull MJ, Bowery MG: Are baclofen-sensitive $\mathrm{GABA}_{\mathrm{B}}$ receptors present on primary afferent terminals of the spinal cord? Nature 307:71-74, 1984

67. Privat JM, Benezech J, Frerebeau P, Gros C: Sectorial posterior rhizotomy, a new technique of surgical treatment for spasticity. Acta Neurochir 35:181-195, 1976

68. Reeves RK, Stolp-Smith KA, Christopherson MW: Hyperthermia, rhabdomyolysis, and disseminated intravascular coagulation associated with baclofen pump catheter failure. Arch Phys Med Rehabil 79:353-356, 1998

69. Rifici C, Kofler M, Kronenberg M, Kofler A, Bramanti P, Sal- 
tuari L: Intrathecal baclofen application in patients with supraspinal spasticity secondary to severe traumatic brain injury. Funct Neurol 9:29-34, 1994

70. Sanger TD, Chen D, Delgado MR, Gaebler-Spira D, Hallett M, Mink JW: Definition and classification of negative motor signs in childhood. Pediatrics, 2006 (in press)

71. Sanger TD, Delgado MR, Gaebler-Spira D, Hallett M, Mink JW: Classification and definition of disorders causing hypertonia in childhood. Pediatrics 111:e89-e97, 2003

72. Siegfried RN, Jacobson L, Chabal C: Development of an acute withdrawal syndrome following the cessation of intrathecal baclofen in a patient with spasticity. Anesthesiology 77: 1048-1050, 1992

73. Spiegel DA, Loder RT, Alley KA, Rowley S, Gutknecht S, Smith-Wright DL, et al: Spinal deformity following selective dorsal rhizotomy. J Pediatr Orthop 24:30-36, 2004

74. Steinbok P: Outcomes after selective dorsal rhizotomy for spastic cerebral palsy. Childs Nerv Sys 17:1-18, 2001

75. Steinbok P, Daneshvar H, Evans D, Kestle JR: Cost analysis of continuous intrathecal baclofen versus selective functional posterior rhizotomy in the treatment of spastic quadriplegia associated with cerebral palsy. Pediatr Neurosurg 22:255-265, 1995

76. Steinbok P, Hicdonmez T, Sawatzky B, Beauchamp R, Wickenheiser D: Spinal deformities after selective dorsal rhizotomy for spastic cerebral palsy. J Neurosurg 102 (4 Suppl): 363-373, 2005

77. Steinbok P, Kestle JR: Variation between centers in electrophysiologic techniques used in lumbosacral selective dorsal rhizotomy for spastic cerebral palsy. Pediatr Neurosurg 25: 233-239, 1996

78. Steinbok P, Keyes R, Langill L, Cochrane DD: The validity of electrophysiological criteria used in selective functional posterior rhizotomy for treatment of spastic cerebral palsy. J Neurosurg 81:354-361, 1994

79. Steinbok P, Reiner AM, Beauchamp R, Armstrong RW, Cochrane DD, Kestle J: A randomized clinical trial to compare selective posterior rhizotomy plus physiotherapy with physiotherapy alone in children with spastic diplegic cerebral palsy. Dev Med Child Neurol 39:178-184, 1997

80. Steinbok P, Schrag C: Complications after selective posterior rhizotomy for spasticity in children with cerebral palsy. Pediatr Neurosurg 28:300-313, 1998

81. Steinbok P, Sgouros S: International questionnaire of selective dorsal rhizotomy and intrathecal baclofen for spastic cerebral palsy. Childs Nerv Sys 19:634, 2003

82. Tardieu C, Lespargot A, Tabary C, Bret MD: For how long must the soleus muscle be stretched each day to prevent contracture? Dev Med Child Neurol 30:3-10, 1988

83. Turi M, Kalen V: The risk of spinal deformity after selective dorsal rhizotomy. J Pediatr Orthop 20:104-107, 2000

84. Vargus-Adams JN, Michaud LJ, Kinnett DG, McMahon MA, Cook FE: Effects of oral baclofen on children with cerebral palsy. Dev Med Child Neurol 46:787, 2004

85. Verrotti A, Greco R, Spalice A, Chiarelli F, Iannetti P: Pharmacotherapy of spasticity in children with cerebral palsy. Pediatr Neurol 34:1-6, 2006

86. Weiss IP, Schiff SJ: Reflex variability in selective dorsal rhizotomy J Neurosurg 79:346-353, 1993

87. Wright FV, Sheil EM, Drake JM, Wedge JH, Naumann S: Evaluation of selective dorsal rhizotomy for the reduction of spasticity in cerebral palsy: a randomized controlled trial. Dev Med Child Neurolo 40:239-247, 1998

88. Yasuoka S, Peterson, HA, MacCarty, CS: Incidence of spinal column deformity after multilevel laminectomy in children and adults. J Neurosurg 57:441-445, 1982

Manuscript received June 16, 2006.

Accepted in final form July 14, 2006.

Address reprint requests to: Paul Steinbok, M.B.B.S, Division of Pediatric Neurosurgery, 4480 Oak Street, \#K3-159, Vancouver, British Columbia, Canada V6H 3V4. email: psteinbok@cw.bc.ca. 